\title{
Satisfaction of astigmatic patients with toric nesofilcon A contact lenses
}

\author{
Jill Saxon \\ Marjorie J Rah \\ William T Reindel
}

Vision Care, Bausch \& Lomb Incorporated, Rochester, NY, USA
Correspondence: Marjorie J Rah

Vision Care, Bausch \& Lomb Incorporated, 1400 North Goodman

Street, Rochester, NY 14609, USA

Tel +l $5854 \mid 36397$

Email marjorie.rah@bausch.com
This article was published in the following Dove Medical Press journal: Clinical Optometry

Purpose: The purpose of this evaluation was to compare the experience of habitual contact lens wearers with that of nonwearers when fitted with a novel toric nesofilcon A contact lens (Biotrue ONEday for Astigmatism lens; Bausch \& Lomb Incorporated, Rochester, NY, USA), for wearer comfort, vision, and satisfaction in a real-world setting.

Materials and methods: Participating eye care practitioners (ECPs) prescribed toric nesofilcon A lenses to their astigmatic patients as part of their routine clinical practices. Accordingly, 1,253 patients successfully completed the evaluation; of these, $51 \%$ wore contact lenses habitually, $41 \%$ wore eyeglasses, and $8 \%$ had no prior vision correction. All wore the lenses for at least 4 days, and $74 \%$ wore them for an average of 9 hours or more per day. After at least 4 days of wear, each patient completed an online survey to evaluate his or her level of satisfaction regarding comfort and vision. As this postmarket evaluation was observational, data were analyzed to determine whether more patients than not agreed with individual statements regarding lens performance, and whether there was any difference in response between habitual contact lens wearers and nonwearers.

Results: As a measure of general satisfaction, $96 \%$ of patients indicated that their overall opinion of the toric nesofilcon A lens was good to excellent. Further, more patients than not agreed that the lens performed well with regard to all aspects of vision and comfort queried $(P<0.001)$. There was no difference in response between habitual contact lens wearers and nonwearers.

Conclusion: All astigmatic patients with spherical contact lenses, other toric lenses, or eyeglasses, as well as those who had no prior correction, who had converted to the toric nesofilcon A lens expressed a high level of satisfaction with vision and comfort. ECPs should expect high success rates when converting astigmatic patients to the novel toric nesofilcon A lens.

Keywords: real-world evidence, clinical, survey

\section{Introduction}

\section{Benefits of contact lenses vs eyeglasses}

Of all medical devices used in the world today, contact lenses are one of the most ubiquitous. An estimated 45 million people wear contact lenses in the USA alone, ${ }^{1}$ while an estimated 140 million wear contact lenses worldwide. ${ }^{2}$ Individuals wear contact lenses for both medical and cosmetic reasons. In addition to providing sharp and unobstructed vision, with no eyeglass lens outline in the periphery and no fogging in humid environments or inclement weather, contact lenses are more amenable to an active lifestyle, eg, sports and other activities, are often more comfortable than eyeglasses, and preserve natural appearance. While half of the adult and teen respondents to a recent survey 
believe that they look better without eyeglasses, ${ }^{3}$ appearance is especially important to children and teenagers, as they perceive improved quality of life (appearance, satisfaction, activities, and peer perceptions) while wearing contact lenses as opposed to while wearing eyeglasses. ${ }^{4,5}$

Astigmatism is common among patients requiring vision correction. Examinations of 179 prospective contact lens patients found that $39 \%$ had astigmatism up to $0.50 \mathrm{D}, 37 \%$ between 0.50 and $1.00 \mathrm{D}$, and $25 \% 1.25 \mathrm{D}$ or greater. ${ }^{6}$ While eye care practitioners (ECPs) prescribe low astigmatism correction for eyeglass lenses, such options are not as widely available in contact lenses. Contact lens wearers with low astigmatism $(\leq 0.50 \mathrm{D})$ are well served by spherical contact lenses, while those with higher astigmatism $(>0.50 \mathrm{D})$ are candidates for toric contact lenses. Holden ${ }^{6}$ calculated that if $0.75 \mathrm{D}$ or greater astigmatism is deemed in need of correction, $45 \%$ of all contact lens wearers would require toric lenses. Young et $\mathrm{al}^{7}$ similarly reported that $47 \%$ of patients had astigmatism of $0.75 \mathrm{D}$ or greater in one eye.

Efron et $\mathrm{al}^{8}$ proposed four factors preventing correction of low-to-moderate astigmatism. 1) Practitioners deem that the marginal increase in visual acuity after correction does not justify either the complications of variability or axis mislocation associated with toric lenses, or the added chair time needed to fit toric lenses; 2) practitioners mistakenly believe that certain spherical silicone hydrogel lenses mask astigmatism; 3) the range of toric lens powers and axes available in daily disposable lens models preferred by practitioners and patients is limited; and 4) practitioners prefer the simplicity of spherical lenses in patients with low refractive cylinder in one eye. Morgan and Efron ${ }^{9}$ also proposed that wearers deem the marginal increase in visual acuity gained after correcting astigmatism $<1.0 \mathrm{D}$ insufficient to justify the marginally higher cost of toric lenses. Practitioner reluctance to prescribe toric lenses to astigmatic spherical lens and eyeglass wearers may also be rooted in historic toric lens orientation variability and fitting difficulty. ${ }^{10}$

There is no consensus as to the minimum amount of astigmatism where the benefit of correction outweighs the aforementioned perceived barriers. In one study, ${ }^{11}$ correction $<0.3 \mathrm{D}$ by dual rotating cylindrical lenses did not meaningfully improve visual acuity, and the authors recommended that astigmatism $<0.5 \mathrm{D}$ be left uncorrected in refractive and cataract surgery. In a different study, ${ }^{12}$ subjects with low-to-moderate astigmatism $(-0.75 \mathrm{D}$ to $-1.00 \mathrm{D})$ wore commercial toric contact lenses, aspheric contact lenses, or eyeglasses serially and in random order with eyes dilated. Both low- and high-contrast visual acuities were similar for the three lens types at $2 \mathrm{~mm}$ artificial pupil size, but both acuities were inferior to the aspheric lens at $4 \mathrm{~mm}$ and $6 \mathrm{~mm}$ pupil size compared with the toric lens and eyeglasses, which were comparable. Similarly, subjects with low-to-moderate astigmatism $(-0.75 \mathrm{D}$ to $-1.25 \mathrm{D})$ wore commercial spherical and toric lenses of the same hilafilcon B material serially and in random order. Of these, 59\% reported better vision with the toric lens, $20 \%$ reported better vision with the spherical lens, and $22 \%$ perceived no difference between lenses. ${ }^{13}$ More recently, $92 \%$ of habitual contact lens wearers with low-to-moderate astigmatism $(-0.75 \mathrm{D}$ to $-1.00 \mathrm{D})$, shown the difference between the visions with spherical and toric lenses in a vision test developed for such purpose, preferred a toric lens for viewing "real-world" stimuli. ${ }^{14}$ Given both ECP-measured and patient-reported improvement in visual acuity with contact lens correction of low-to-moderate astigmatism, toric contact lenses appear superior to spherical lenses in astigmats, even for low-to-moderate astigmatism.

Innovations in contact lens materials and lens designs create opportunities for ECPs to address the vision needs of their patients. One such material is nesofilcon $\mathrm{A}$, the highwater-content, traditional hydrogel used in the Biotrue ONEday for Astigmatism lens (Bausch \& Lomb Incorporated). ${ }^{15,16}$ The lens includes Pluronic F127, a polyethylene oxide (PEO)-polypropylene oxide-PEO block copolymer surfactant in a lens fabricated from hydroxyethyl methacrylate and $N$-vinylpyrrolidone monomers, which results in $78 \%$ water content throughout the lens. ${ }^{17}$ This results in a lens that maintains essentially all of its initial water over the first 15 minutes of wear and maintains $98 \%$ of the water content over 16 hours of wear. ${ }^{17-19}$ The Biotrue ONEday for Astigmatism lens incorporates the material into a unique toric design with a periballast geometry for comfort and vision stability, in addition to having integrated spherical aberration control to reduce halos and glare. ${ }^{20}$

In the absence of large, randomized clinical studies, many ECPs rely upon real-world, patient experience of contact lenses fit by peers before adopting new, innovative lenses. Real-world, nonrandomized, prospective studies are used to evaluate product performance in both broader patient populations and special patient subsets. ${ }^{21-26}$ Recently, they have gained popularity among medical device manufacturers as they can improve understanding of the risk-benefit profiles of devices. While real-world data are collected primarily for nonregulatory purposes, the US Food and Drug Administration recognizes that such data provide insights into clinical outcomes and can potentially be used to support regulatory submissions. ${ }^{27}$ 
In the present prospective evaluation, a novel toric nesofilcon A contact lens was evaluated for wearer comfort, vision, and satisfaction. While the lens was commercially available at the time of the evaluation, it was beneficial to evaluate how different patient populations would perceive lens performance. Therefore, the experience of habitual contact lens wearers was compared with that of nonwearers when fitted with the toric nesofilcon A contact lens.

\section{Patients and methods Patient selection}

ECPs prescribed toric nesofilcon A lenses to astigmatic patients whom they deemed appropriate as part of their respective routine clinical practices, where the need for a toric lens was left to each individual ECP's discretion. These patients were invited to participate in this nonrandomized, prospective evaluation of toric nesofilcon A lenses. Willing patients consented to participate in a postmarket survey by agreeing to the following through a Web-based platform: 1) "I agree to allow Bausch + Lomb use of my comments and my identity will remain anonymous"; 2) "I agree to allow Bausch + Lomb to contact me". Patients who did not agree were not further queried and did not participate in the evaluation.

Survey participants were dispensed a supply of daily disposable, toric nesofilcon A lenses and told to wear the lenses as prescribed by their respective ECPs for 4 days. At the conclusion of the 4-day period, participants were instructed to complete an online survey designed to evaluate their level of satisfaction regarding comfort and vision while wearing the lenses (Supplementary material). Participants self-identified their habitual vision correction method. In addition, those who habitually wore contact lenses self-identified their habitual lens brand.

\section{Data analysis}

Patients answered each survey question as agree (strongly agree, agree, or slightly agree) or disagree (strongly disagree, disagree, or slightly disagree). Data from this survey were compiled and analyzed to determine the incidences of positive (agree) responses. Data were further segmented into three patient subsets (those who previously wore contact lenses, those who previously wore eyeglasses, or those who previously had no prior vision correction), each of which was analyzed independent of the others.

\section{Statistical analysis}

For each group, two-tailed $P$-values were calculated to determine the probability that the percentage of positive (agree) responses was $>50 \%$ for each question. In addition, a twosample $t$-test was used to determine whether responses from patients who habitually wore contact lenses differed from those who did not. Patients who habitually wore glasses only or had no prior vision correction were combined as one group for this comparison. Differences were considered statistically significant if $P \leq 0.01$.

\section{Results}

\section{Patient demographics}

Totally, 1,253 patients successfully completed the evaluation (ie, wore toric nesofilcon A lenses for a 4-day period and answered all survey questions). Of these, 641 (51\%) habitually wore contact lenses, 511 (41\%) habitually wore eyeglasses, and 101 (8\%) had no prior vision correction. Of the contact lens wearers, $69 \%$ indicated that they habitually wore toric lenses, $22 \%$ spherical lenses, and $9 \%$ did not identify their lenses.

For the purpose of comparison, contact lens wearers were compared with nonwearers (including habitual eyeglassonly wearers and patients with no prior vision correction). The average patient age was 32.6 years $(33.2 \pm 11.0$ years vs $31.9 \pm 11.6$ years for habitual contact lens wearers and nonwearers, respectively; $P=0.046$ ). Similar to the reported two-thirds incidence of female vs male contact lens wearers in the USA, ${ }^{28} 64 \%$ of patients were female (67\% vs $60 \%$ for wearers and nonwearers, respectively, $P=0.011)$. During the evaluation, more patients (44\%) wore lenses for 9-12 hours per day ( $42 \%$ vs $46 \%$ for contact lens wearers and nonwearers, respectively; $P<0.001)$ than for $<9$ hours $(29 \%)$ or $>12$ hours $(29 \%)$.

All three patient groups (contact lens wearers, eyeglass wearers, and uncorrected patients) answered all survey queries with $>50 \%$ positive response $(P<0.001)$. Patient vision and comfort outcomes appear in Tables 1-3. The durations of patients' daily, real-world activities appear in Table 4. Habitual contact lens wearers and nonwearers spent similar amounts of time for various activities, differing only in that habitual contact lens wearers used a computer for longer daily duration at the office (4.9 hours vs 4.4 hours, respectively, $P=0.008$; Table 4 ). This small difference, while statistically significant, may be of little or no clinical consequence.

Thus, $96 \%$ of the patients who participated in this evaluation indicated that their overall opinion of the toric nesofilcon A lens was good to excellent, indicating that the lens represents a good option for most astigmatic patients. Further, more patients than not agreed that all individual aspects of 
Table I Proportion of patients reporting clear vision under different real-world conditions while wearing toric nesofilcon A lenses (percentage \pm margin of error at $95 \%$ confidence)

\begin{tabular}{|c|c|c|c|c|}
\hline Condition & $\begin{array}{l}\text { Agree, } \% \\
(\text { total) } \\
(n=l, 253)\end{array}$ & $\begin{array}{l}\text { Agree, } \% \\
(C L \text { wearers }) \\
(n=64 I)\end{array}$ & $\begin{array}{l}\text { Agree, } \% \\
\text { (eyeglass plus no } \\
\text { prior correction) } \\
(n-=6 \mid 2)\end{array}$ & $P$-value ${ }^{a}$ \\
\hline \multicolumn{5}{|l|}{ Specific distance situations } \\
\hline Distant - driving & $97 \pm 0.9$ & $97 \pm 1.3$ & $97 \pm 1.4$ & 0.88 \\
\hline Intermediate - using computer or tablet & $96 \pm 1.1$ & $96 \pm 1.4$ & $95 \pm 1.7$ & 0.38 \\
\hline $\begin{array}{l}\text { Near - using cell phone (text, email, and } \\
\text { browse) }\end{array}$ & $96 \pm 1.1$ & $96 \pm 1.4$ & $96 \pm 1.6$ & 0.46 \\
\hline \multicolumn{5}{|l|}{ General situations } \\
\hline During physical activity (eg, sports) & $96 \pm 1.2$ & $97 \pm 1.4$ & $96 \pm 1.6$ & 0.54 \\
\hline Throughout the day & $95 \pm 1.2$ & $95 \pm 1.7$ & $95 \pm 1.7$ & 0.85 \\
\hline While lying down & $95 \pm 1.2$ & $96 \pm 1.6$ & $95 \pm 1.7$ & 0.56 \\
\hline Freedom from blurry or fluctuating vision & $93 \pm 1.4$ & $93 \pm 2.0$ & $94 \pm 1.9$ & 0.37 \\
\hline \multicolumn{5}{|l|}{ Low-light situations } \\
\hline Reduced halos and glare, even in low light & $94 \pm 1.3$ & $94 \pm 1.8$ & $94 \pm 1.9$ & 0.97 \\
\hline Night driving & $95 \pm 1.2$ & $95 \pm 1.7$ & $95 \pm 1.8$ & 0.85 \\
\hline
\end{tabular}

Note: aBetween-type $P$-value comparing proportions of $C L$ wearers and nonwearers based upon the chi-squared test.

Abbreviation: $\mathrm{CL}$, contact lens.

Table 2 Proportion of patients reporting comfortable lenses under different real-world conditions while wearing toric nesofilcon A lenses (percentage \pm margin of error at $95 \%$ confidence)

\begin{tabular}{|c|c|c|c|c|}
\hline Condition & $\begin{array}{l}\text { Agree, } \% \\
(\text { total) } \\
(n=I, 253)\end{array}$ & $\begin{array}{l}\text { Agree, \% } \\
(C L \text { wearers) } \\
(n=64 I)\end{array}$ & $\begin{array}{l}\text { Agree, } \% \\
\text { (eyeglass plus no } \\
\text { prior correction) } \\
(n=6 \mid 2)\end{array}$ & $P$-value ${ }^{a}$ \\
\hline Working long hours on a computer or tablet & $92 \pm 1.5$ & $93 \pm 2.0$ & $92 \pm 2.1$ & 0.82 \\
\hline Using cell phone (text, email, and browse) & $94 \pm 1.3$ & $94 \pm 1.9$ & $94 \pm 1.8$ & 0.69 \\
\hline All day long & $92 \pm 1.5$ & $91 \pm 2.2$ & $94 \pm 2.2$ & 0.08 \\
\hline At the end of the day & $90 \pm 1.7$ & $88 \pm 2.5$ & $91 \pm 2.2$ & 0.09 \\
\hline
\end{tabular}

Note: 'Between-type $P$-value comparing proportions of $C L$ wearers and nonwearers based upon the chi-squared test.

Abbreviation: $\mathrm{CL}$, contact lens.

Table 3 Proportion of patients reporting good-to-excellent real-world lens performance characteristics while wearing toric nesofilcon A lenses (percentage \pm margin of error at $95 \%$ confidence)

\begin{tabular}{|c|c|c|c|c|}
\hline Condition & $\begin{array}{l}\text { Agree, } \% \\
(\text { total) } \\
(n=I, 253)\end{array}$ & $\begin{array}{l}\text { Agree, } \% \\
(C L \text { wearers) } \\
(n=64 I)\end{array}$ & $\begin{array}{l}\text { Agree, } \% \\
\text { (eyeglass plus } \\
\text { prior correction) } \\
(n=6 \mid 2)\end{array}$ & $P$-value ${ }^{a}$ \\
\hline Are just as comfortable at the end of the day as at the beginning of the day & $88 \pm 1.8$ & $87 \pm 2.6$ & $89 \pm 2.5$ & 0.36 \\
\hline Prevent eyes from feeling tired or fatigued & $91 \pm 1.6$ & $90 \pm 2.3$ & $91 \pm 2.2$ & 0.48 \\
\hline Keep eyes moist and comfortable all day & $88 \pm 1.8$ & $88 \pm 2.6$ & $89 \pm 2.4$ & 0.30 \\
\hline
\end{tabular}

Note: ${ }^{B}$ Between-type $P$-value comparing proportions of $C L$ wearers and nonwearers based upon the chi-squared test.

Abbreviation: $\mathrm{CL}$, contact lens.

vision and comfort were good to excellent $(P<0.001)$. With respect to vision at near (cell phone), intermediate (computer or tablet), and far (driving) distance situations, there was no difference in response between habitual contact lens wearers and nonwearers $(95 \%$ or greater positive response;
$P=0.46,0.38$, and 0.88 for the three respective distances). There was also no difference in response between groups with respect to clear vision in general situations, ie, during physical activity, throughout the day, and while lying down ( $95 \%$ or greater positive response; $P=0.54,0.85$, and 0.56 
Table 4 Daily duration of patient's real-world activities, in hours

\begin{tabular}{|c|c|c|c|c|}
\hline \multirow[t]{2}{*}{ Activity } & \multicolumn{3}{|c|}{ Average duration, hours } & \multirow[t]{2}{*}{$P$-value ${ }^{a}$} \\
\hline & $\begin{array}{l}\text { Total } \\
(n=I, 253)\end{array}$ & $\begin{array}{l}\text { CL } \\
\text { wearers } \\
(n=641)\end{array}$ & $\begin{array}{l}\text { Eyeglass plus no } \\
\text { prior correction } \\
(n=6 \mid 2)\end{array}$ & \\
\hline Driving & 1.9 & 1.9 & 1.9 & 0.72 \\
\hline Watching TV & 2.0 & 1.9 & 2.1 & 0.03 \\
\hline Playing sports, running, other exercise & 1.3 & 1.2 & 1.3 & 0.05 \\
\hline Using a computer or laptop at the office & 4.7 & 4.9 & 4.4 & $0.008^{b}$ \\
\hline Using a computer or laptop at home & 1.7 & 1.7 & 1.7 & 0.38 \\
\hline Looking at a smartphone, tablet, or e-book & 2.5 & 2.5 & 2.5 & 0.70 \\
\hline Reading books, magazines, and newspapers & 0.9 & 0.9 & 0.9 & 0.88 \\
\hline
\end{tabular}

Notes: aBetween-type $P$-value comparing proportions of the $C L$ wearer and nonwearer groups based upon the chi-squared test. bStatistically significant difference between $\mathrm{CL}$ wearer and nonwearer groups.

Abbreviation: $\mathrm{CL}$, contact lens.

for the three respective situations); similar was the case with respect to freedom from blurry or fluctuating vision $(92 \%$ vs $93 \%$, respectively; $P=0.37$ ). Both groups similarly agreed that they had clear vision while wearing the lens in low-light situations ( $94 \%$ or greater positive response; $P=0.97$ and 0.85 for freedom from low-light halos/glare and driving at night, respectively). Both groups found the toric nesofilcon A lens comparably comfortable while working long hours on a tablet or computer, or while using a cell phone $(91 \%$ or greater positive response; $P=0.82$ and 0.69 , respectively), as well as at the beginning of, during, and at the end of the day ( $87 \%$ or greater positive response; $P=0.36,0.48$, and 0.30 for the three respective times of day).

\section{Discussion}

ECPs often prefer to keep a satisfied lens wearer in a habitual lens but maintain the option to consider different lenses as the patient's vision changes. In the case of a spherical lens wearer with moderate astigmatism, the ECP must weigh the benefit of astigmatism correction against the potential costs of using a toric lens. Advancements in both lens materials and designs since the turn of the century have improved toric lens fitting protocols and increased toric lens utilization. ${ }^{8,29} \mathrm{In}$ practice diagnostic fitting set inventories of some lens models now accommodate $>90 \%$ of astigmatic patients. ${ }^{7}$ Practitioner confidence in toric lenses is growing and greater than in the past. ${ }^{29}$ For example, a recent study of 200 subjects across 16 investigational sites found that $88 \%$ of subjects were fit with one toric lens model on first attempt. ${ }^{30}$

Refitting a satisfied patient to a different lens option always presents some risk to patient satisfaction. Conversely, eyestrain and/or blur resulting from uncorrected astigmatism in an astigmatic spherical lens wearer may lead to contact lens dissatisfaction, and not converting to a toric lens risks converting that wearer to a lens dropout. One barrier to contact lens wear among astigmats is the mistaken belief that astigmatism precludes such wear. Almost half of habitual eyeglass-wearing astigmats in one survey indicated that their vision may be an obstacle to contact lens wear, and of these, over two-thirds cited their astigmatism as the primary factor. ${ }^{3}$ Conversely, prospective contact lens wearers cited appearance, convenience, and not wanting to wear glasses as reasons for interest in contact lenses. While today's patients are interested in learning about advancements in lens technologies and trying those lens options, most expect only periodic updates to their lens prescription. ${ }^{31}$ Surprisingly, "not aware there were lenses for astigmatism" (28\%), "not aware had astigmatism" (22\%), and "my eye care practitioner never offered me toric lenses" $(12 \%)$ are common reasons that spherical lens wearers gave for not wearing toric lenses, ${ }^{30}$ illustrating the need for better communication between practitioner and patient. Further, "contact lenses were difficult to use or inconvenient" (51\%) and "contact lenses were uncomfortable to wear" (39\%) are reasons that former lens wearers gave for dropping out of lens wear. Modern lens materials and daily-disposable toric lens designs have the potential to largely solve both problems for most wearers.

In this evaluation, astigmatic patients with a history of contact lens wear or eyeglass wear, as well as patients not using lens correction, were fitted with toric nesofilcon A lenses. After 4 days of wear, this population - when asked about lens performance across a wide range of real-world activities - agreed that the lenses provided clear vision and comfort. Ninety-six percent of habitual contact lens wearers and $95 \%$ of nonwearers indicated that their overall opinion of the lens is good to excellent, compared with $84 \%$ in an older 
study of a different lens model. ${ }^{32}$ Moreover, $\geq 93 \%$ of patients had clear vision in the following conditions: under conditions of near, intermediate, and far distance; under low-, normal-, and bright-light conditions; and during activities such as digital display viewing, driving, and sports or recreational activities (Table 1). There was no difference in response between contact lens wearers and nonwearers for any of the nine aspects queried in Table 1 ( $P$-value range: $0.38-0.97)$.

Today's contact lens wearers demand more from their lenses, primarily due to near-constant use of digital devices. Between television, computers, smartphones, tablets, and e-readers, participants in this evaluation spent $>10$ hours daily viewing digital displays (11.0 hours vs 10.7 hours for habitual contact lens wearers and nonwearers, respectively), compared with 9.9 hours for the general US population. ${ }^{33}$ Digital display viewing reduces blink rate and blink completeness, which can lead to lens dehydration, disruption of the prelens tear film, and perturbed vision. ${ }^{34,35}$ Ninety-six percent of patients had clear vision while wearing the toric nesofilcon A lens when using digital technology and 95\% when prone (Table 1), as is common when viewing cell phones, tablets, and e-readers during the evening hours before bedtime or while in bed. The latter is significant because in contrast to the toric nesofilcon A lens, some lenses tend to move on the eye when the wearer changes positions as in lying down. ${ }^{36}$ Further, $\geq 92 \%$ of patients agreed that the lenses were comfortable while using different digital technologies and throughout the day (Table 2). There was no difference in response between habitual contact lens wearers and nonwearers for any of the four aspects queried in Table 2 ( $P$-value range: $0.08-0.82$ ).

Like the digital display viewing environment, the sports and recreation environment can challenge both contact lens and eyeglass wearers. Athletes demand sharper and clearer vision than does the general public. Activities that involve rapid and jarring motions can cause eyeglasses to move (perturbing vision) and ultimately dislodge from the face. While contact lenses largely solve that problem, the sports/ recreation environment can promote contact lens dehydration, resulting in visual aberration and discomfort. Dust and dry air can be particularly challenging for the active contact lens wearer. ${ }^{37}$ In this evaluation, patients spent over an hour daily participating in recreational activities (1.2 hours vs 1.3 hours for habitual contact lens wearers and nonwearers, respectively). Furthermore, $97 \%$ and $96 \%$ of these respective populations had clear vision while wearing nesofilcon A lenses during physical activities (Table 1), suggesting that the lens effectively maintains its water during such activities.
Similar to comparisons of digital technology use, there was no difference in response between contact lens wearers and nonwearers $(P=0.54)$.

Common activities such as driving also expose patients to varying environments that affect contact lens hydration. Flow of dry air within an automobile cabin, either blown from the cabin heating or cooling systems or entering through open windows, promotes dehydration of contact lenses. In this evaluation, habitual contact lens wearers and nonwearers alike each spent an average of 1.9 hours daily driving. Similar to the sports and recreation environment, 97\% of participants from both groups had the same clear vision while wearing toric nesofilcon A lenses when driving in normal light $(P=0.88)$ and $95 \%$ when driving at night $(P=0.85$; Table 1). Further, $94 \%$ of both groups agreed that the lens helped reduce halos and glare in low-light conditions $(P=0.97)$.

The postmarket survey of the present evaluation suggests that both habitual contact lens wearers and nonwearers are likely to be fit successfully and be satisfied with the toric nesofilcon A lenses. While $96 \%$ of respondents had a positive opinion of the lens, there was no difference in response between the two groups. In a previous study of a different toric lens, nonwearers had $83 \%$ positive opinion of the lens after 1 week; moreover, $70 \%$ were successfully fit after 1 month vs $80 \%$ of spherical lens wearers converting to the toric lens. ${ }^{30}$ The study authors concluded that a high fraction of astigmats could be easily fitted with a toric lens; we concur.

This postmarket evaluation of toric nesofilcon A lenses in a real-world setting indicates a high level of consumer satisfaction with the lens. However, there are factors that could have influenced participant responses. Individual ECPs determined which patients were appropriate to wear the toric nesofilcon A lens and which to invite to participate in the study. This evaluation was not masked; therefore, initial ECP and patient perceptions of the lens may have affected participant opinions. Because participants self-identified their habitual vision correction method, some habitual contact lenses wearers may have misidentified their lens manufacturer or lens model (eg, spherical vs toric). This did not affect the data analysis because all habitual contact lens wearers knew that they were habitual lens wearers, and spherical and toric contact lens wearer responses were grouped without considering the lens manufacturer or model. Additionally, this evaluation did not consider participant satisfaction with habitual mode of vision correction. Participants may have expressed a high degree of satisfaction with the toric nesofilcon A lens relative to suboptimal habitual vision correction, although we consider this unlikely since participants 
were recruited from patients already visiting their respective ECPs. This evaluation was designed only to determine how astigmats who were fitted with the toric nesofilcon A lens perceived lens performance and was not meant to compare wearer experience with this lens to that with any other lens. As few studies comparing different toric contact lenses, and none comparing any toric lens to the toric nesofilcon A lens, appear in published literature, wearer preference for specific toric lens models is not known.

\section{Conclusion}

Astigmatic patients converted from their habitual vision correction (spherical contact lenses, other toric lenses, eyeglasses, or no correction) to the toric nesofilcon A lens express a high level of satisfaction after 4 days of lens wear. Improvements in lens materials and designs should alleviate ECP concerns regarding converting astigmatic patients with eyeglasses and spherical lenses to toric lenses. ECPs can successfully fit nearly all astigmatic patients (uncorrected, nonwearers of lenses, eyeglass wearers, spherical lens wearers, and other toric lens wearers) into toric nesofilcon A lenses and expect that the majority of patients will have clear, comfortable vision while using the lenses under all wearing conditions.

\section{Acknowledgments}

This work was funded by Bausch \& Lomb Incorporated. The abstract of this paper was presented at the Global Specialty Lens Symposium at Las Vegas, NV, USA, on January 25-28, 2018 , as a poster presentation with interim findings.

\section{Disclosure}

All authors are direct employees of Bausch \& Lomb Incorporated. The authors report no other conflicts of interest in this work.

\section{References}

1. Aoa.org [homepage on the Internet]. Facts and Stats. St. Louis, MO: American Optometric Association; 2018 [updated August, 2017; cited August 1, 2018]. Available from: https://www.aoa.org/patients-andpublic/caring-for-your-vision/contact-lenses/facts-and-stats. Accessed August 1, 2018.

2. Subbaraman LN. In focus with current contact lens materials and designs. An overview of new contact lens technologies, with a focus on what lens characteristics impact wearing comfort. Cont Lens Spectr. 2017;32(537):2255-5.

3. The 2018 Gallup Target Market Report on the Market for Toric Contact Lenses, Multi-sponsor Surveys, Inc.; 2018. Available from: http:// www.multisponsor.com/wp-content/uploads/2016/09/Toric-ContactLens-16023.pdf. Accessed August 1, 2018.

4. Plowright AJ, Maldonado-Codina C, Howarth GF, Kern J, Morgan PB. Daily disposable contact lenses versus spectacles in teenagers. Optom Vis Sci. 2015;92(1):44-52.
5. Walline JJ, Gaume A, Jones LA, et al. Benefits of contact lens wear for children and teens. Eye Contact Lens. 2007;33(6 Pt 1):317-321.

6. Holden B. The principles and practice of correcting astigmatism with soft contact lenses. Aust J Optom. 1975;58:279-299.

7. Young G, Sulley A, Hunt C. Prevalence of astigmatism in relation to soft contact lens fitting. Eye Contact Lens. 2011;37(1):20-25.

8. Efron N, Morgan PB, Helland M, et al. Soft toric contact lens prescribing in different countries. Cont Lens Anterior Eye. 2011;34(1):36-38.

9. Morgan PB, Efron N. Prescribing soft contact lenses for astigmatism. Cont Lens Anterior Eye. 2009;32(2):97-98.

10. Tan J, Papas E, Carnt N, et al. Performance standards for toric soft contact lenses. Optom Vis Sci. 2007;84(5):422-428.

11. Villegas EA, Alcón E, Artal P. Minimum amount of astigmatism that should be corrected. J Cataract Refract Surg. 2014;40(1):13-19.

12. Morgan PB, Efron SE, Efron N, Hill EA. Inefficacy of aspheric soft contact lenses for the correction of low levels of astigmatism. Optom Vis Sci. 2005;82(9):823-828.

13. Cho P, Cheung SW, Charm J. Visual outcome of Soflens Daily Disposable and Soflens Daily Disposable for Astigmatism in subjects with low astigmatism. Clin Exp Optom. 2012;95(1):43-47.

14. Milton A, Murphy M, Rose B, et al. Demonstrating correction of low levels of astigmatism with realistic scenes. Cont Lens Anterior Eye. 2016;39(1):26-37.

15. FDA 510(k) Summary K113703. Bausch + Lomb nesofilcon A contact lens; 2012. Available from: https://www.accessdata.fda.gov/cdrh_docs/ pdf11/K113703.pdf. Accessed August 1, 2018.

16. FDA 510(k) Summary K151918. Bausch + Lomb Biotrue ONEday for Presbyopia (nesofilcon A) Soft (Hydrophilic) Contact Lens; 2013. Available from: https://www.accessdata.fda.gov/cdrh_docs/pdf13/k132715. pdf. Accessed August 1, 2018.

17. Schafer J, Steffen R, Reindel W, Chinn J. Evaluation of surface water characteristics of novel daily disposable contact lens materials, using refractive index shifts after wear. Clin Ophthalmol. 2015;9:1973-1979.

18. Schafer J, Steffen R, Vaz T, Reindel W. Comparing on eye dehydration and corneal staining of two high water hydrogel contact lenses in a low humidity environment. Optom Vis Sci. 2011;88115540(e-abstract).

19. Steffen R, Schafer J. Comparing on eye dehydration of two hydrogel contact lenses. Poster Presented at: Global Specialty Lens Symposium; 2014; Las Vegas, NV.

20. FDA 510(k) Summary K143632. Bausch + Lomb Biotrue Oneday For Astigmatism (nesofilcon A) Soft (hydrophilic) Contact Lens; 2015. Available from: https://www.accessdata.fda.gov/cdrh_docs/pdf14/ K143632.pdf. Accessed August 1, 2018.

21. Rah MJ, Saxon J, Riendel WT. Real-world performance captures the presbyopic opportunity. Cont Lens Spect. 2016;31(13SE):36-40.

22. Beusterien K, Tsay S, Gholizadeh S, Su Y. Real-world experience with colorectal cancer chemotherapies: patient web forum analysis. Ecancermedicalscience. 2013;7:361.

23. Boeru G, Milanov I, De Robertis F. ExtaviJect(R) $30 \mathrm{G}$ device for subcutaneous self-injection of interferon beta- $1 \mathrm{~b}$ for multiple sclerosis: a prospective European study. Med Devices (Auckl). 2013;6:175-184.

24. Chaudhuri N, Duck A, Frank R, Holme J, Leonard C. Real world experiences: pirfenidone is well tolerated in patients with idiopathic pulmonary fibrosis. Respir Med. 2014;108(1):224-226.

25. Ge JB, Zhang F, Qian JY, Ge L, Liu XB, Zhou J. Six-month clinical outcomes of Firebird 2TM sirolimus-eluting stent implantation in real-world patients with coronary artery diseases. Chin Med J (Engl). 2011;124(6):831-835.

26. Han YL, Chen JY, Xu B, et al. Real world clinical performance of the zotarolimus eluting coronary stent system in Chinese patients: a prospective, multicenter registry study. Chin Med J (Engl). 2011;124(20):3255-3259.

27. FDA Guidance Document. Use of Real-World Evidence to Support Regulatory Decision-Making for Medical Devices. Guidance for Industry and Food and Drug Administration; 2017. Available from: https:// www.fda.gov/downloads/medicaldevices/deviceregulationandguidance/ guidancedocuments/ucm513027.pdf. Accessed August 1, 2018. 
28. Cdc.gov [homepage on the Internet]. Healthy Contact Lens Wear and Care. Atlanta, GA: Centers for Disease Control and Prevention; 2015 [updated July 26, 2015; cited August 1, 2018]. Available from: https:// www.cdc.gov/contactlenses/fast-facts.html. Accessed August 1, 2018.

29. Morgan PB, Efron N, Woods CA. An international survey of toric contact lens prescribing. Eye Contact Lens. 2013;39(2):132-137.

30. Sulley A, Young G, Lorenz KO, Hunt C. Clinical evaluation of fitting toric soft contact lenses to current non-users. Ophthalmic Physiol Opt. 2013;33(2):94-103.

31. Rah MJ, Reindel WM. Interest and Acceptance of a New Contact Lens Technology in Today's Practice. Poster presented at the 118th Annual AOA Congress \& 45th Annual AOSA Conference: Optometry's Meeting; June 26, 2015; Seattle, WA.

32. Silbert J, Ghormley NR, Hankin B, Rigel L, Barron C. An evaluation of empirically fitting a posterior toric hydrogel contact lens. J Am Optom Assoc. 1992;63(3):170-175.
33. Ipsos.com [homepage on the Internet]. Socialogue: if you're awake, chances are you are well-connected. New York, NY: Ipsos OTX and Ipsos Global@dvisor. 2015 [updated August 20, 2012; cited August 1, 2018]. Available from: https://www.ipsos.com/en-us/socialogue-ifyoure-awake-chances-are-you-are-well-connected. Accessed August 1, 2018.

34. Argilés M, Cardona G, Pérez-Cabré E, Rodríguez M. Blink rate and incomplete blinks in six different controlled hard-copy and electronic reading conditions. Invest Ophthalmol Vis Sci. 2015;56(11):6679-6685.

35. Portello JK, Rosenfield M, Chu CA. Blink rate, incomplete blinks and computer vision syndrome. Optom Vis Sci. 2013;90(5):482-487.

36. Young G, McIlraith R, Hunt C. Clinical evaluation of factors affecting soft toric lens orientation. Optom Vis Sci. 2009;86(11):E1259-E1266.

37. Bauer IL. Contact lens wearers' experiences while trekking in the Khumbu region/Nepal: a cross-sectional survey. Travel Med Infect Dis. 2015;13(2):178-184. 


\section{Supplementary material}

Survey questions asked of astigmatic habitual contact lens and eyeglass wearers 4 hours after wearing toric nesofilcon A lenses.

1. Have you finalized your prescription for your Biotrue ${ }^{\circledR}$ ONEday for Astigmatism?

2. If you have not finalized your prescription, do you plan to go back to your eye doctor and adjust the prescription?

3. How many days did you wear your Biotrue ONEday for Astigmatism contact lenses?

4. On average, how many hours per day did you wear your Biotrue ONEday for Astigmatism contact lenses?

5. Before wearing Biotrue ONEday for Astigmatism contact lenses, what did you primarily wear to correct your vision?

6. Before wearing Biotrue ONEday for Astigmatism contact lenses, what brand of contact lenses did you wear most often?

7. Are you female/male?

8. Please indicate your age.

9. Biotrue ONEday for Astigmatism contact lenses deliver comfortable vision

9a. even when looking for a long time at a smartphone or tablet.

$9 \mathrm{~b}$. even when working for long hours at a computer.

9 c. throughout the day.

9d. in low-light conditions.

9e. in bright-light conditions.

9f. while doing different physical activities (eg, sports, running, and so on).

10. What is your overall opinion of Biotrue ONEday for Astigmatism contact lenses?

11. Which of the following statements best describes how you feel about Biotrue ONEday for Astigmatism contact lenses compared to the previous brand of contact lenses you wore the most often? I prefer:

12. Which of the following statements best describes how you feel about Biotrue ONEday for Astigmatism contact lenses compared to wearing glasses? I prefer:

13. Biotrue ONEday for Astigmatism contact lenses

13a. provide clear vision when driving.

13b. provide clear vision when driving during the day.

13c. provide clear vision when driving at night.

13d. provide clear vision for physical activities (eg, sports, running, and so on). 13e. provide clear vision when using my cell phone for email, texts, and Internet.

13f. provide clear vision when working on my computer or tablet.

13g. provide clear vision when reading a book.

13h. provide clear vision when watching TV.

13i. provide consistently clear vision throughout the day.

13j. provide consistently clear vision when I lie down.

$13 \mathrm{k}$. help reduce halos and glare, even in low-light conditions.

131. help prevent blurry or fluctuating vision.

14. Biotrue ONEday for Astigmatism contact lenses

14a. are comfortable all day long.

14b. are comfortable even when working for long hours on a computer or tablet.

$14 \mathrm{c}$. are comfortable at the end of the day.

$14 \mathrm{~d}$. prevent my eyes from feeling tired or fatigued

$14 \mathrm{e}$. are comfortable when using my cell phone for email, texts, and Internet.

14f. are just as comfortable at the end of the day as they were at the beginning of the day.

14g. help keep my eyes stay moist and comfortable all day.

15. Please provide your level of agreement with the following statements about your Eye Care Professional. Remember, your answers are completely confidential and will only be reported in aggregate with all other scores.

15a. Overall, I am satisfied with my experience at my Eye Care Professional's office.

15b. I am likely to recommend my Eye Care Professional to friends and family.

15c. I am interested in trying new contact lens innovations.

15d. I feel comfortable talking to my eye doctor if I am unhappy with my lenses.

15e. I believe it is important for my eye doctor to educate me on innovative technologies in eye health.

$15 f$. When I visit my eye doctor, I want to discuss advancements that can make my contact lens more comfortable.

$15 \mathrm{~g}$. When I visit my eye doctor, I want to discuss advancements that can make my contact lens vision better.

$15 \mathrm{~h}$. My eye doctor proactively discusses new contact lens innovations with me. 
16. How many hours do you spend doing each of the following activities on a typical day?

16a. Driving

16b. Watching TV

16c. Playing sports, running, or other exercise

16d. Using a computer or laptop at the office 16e. Using a computer or laptop at home

16f. Looking at a smartphone, tablet, or e-book

16g. Reading books, magazines, newspapers

16h. Playing electronic games

\section{Publish your work in this journal}

Clinical Optometry is an international, peer-reviewed, open access journal publishing original research, basic science, clinical and epidemiological studies, reviews and evaluations on clinical optometry. All aspects of patient care are addressed within the journal as well as the practice of optometry including economic and business analyses. Basic and clinical

Submit your manuscript here: https://www.dovepress.com/clinical-optometry-journal research papers are published that cover all aspects of optics, refraction and its application to the theory and practice of optometry. The manuscript management system is completely online and includes a very quick and fair peer-review system, which is all easy to use. Visit http://www.dovepress. com/testimonials.php to read real quotes from published authors. 